\title{
Experimental Models of Inherited PrP Prion Diseases
}

\author{
Joel C. Watts ${ }^{1}$ and Stanley B. Prusiner ${ }^{2}$ \\ ${ }^{1}$ Tanz Centre for Research in Neurodegenerative Diseases and Department of Biochemistry, University \\ of Toronto, Toronto, Ontario M5T 2S8, Canada \\ ${ }^{2}$ Institute for Neurodegenerative Diseases, Departments of Neurology and Biochemistry and Biophysics, \\ Weill Institute for Neurosciences, University of California, San Francisco, San Francisco, California 94143 \\ Correspondence: stanley.prusiner@ucsf.edu
}

\begin{abstract}
The inherited prion protein (PrP) prion disorders, which include familial Creutzfeldt-Jakob disease, Gerstmann-Sträussler-Scheinker disease, and fatal familial insomnia, constitute $\sim 10 \%-15 \%$ of all PrP prion disease cases in humans. Attempts to generate animal models of these disorders using transgenic mice expressing mutant PrP have produced variable results. Although many lines of mice develop spontaneous signs of neurological illness with accompanying prion disease-specific neuropathological changes, others do not. Furthermore, demonstrating the presence of protease-resistant PrP species and prion infectivity-two of the hallmarks of the PrP prion disorders-in the brains of spontaneously sick mice has proven particularly challenging. Here, we review the progress that has been made toward developing accurate mouse models of the inherited PrP prion disorders.
\end{abstract}

$T^{\mathrm{h}}$ he prion protein $(\mathrm{PrP})$ prion disorders are a group of invariably fatal neurodegenerative conditions that affect humans and animals. In these diseases, $\operatorname{PrP}$ undergoes a conformational rearrangement from a predominantly $\alpha$-helical cellular isoform $\left(\mathrm{PrP}^{\mathrm{C}}\right)$ into a misfolded, $\beta$ sheet-rich isoform $\left(\mathrm{PrP}^{\mathrm{Sc}}\right)$ that aggregates and causes disease (Colby and Prusiner 2011). Like other prions, $\mathrm{PrP}^{\mathrm{Sc}}$ is self-propagating and can catalyze its own formation by binding to $\operatorname{PrP}^{\mathrm{C}}$ and templating its conversion to $\operatorname{PrP}^{\mathrm{Sc}}$. This process permits a cascade of $\operatorname{PrP}^{\mathrm{Sc}}$ production and its subsequent spread throughout the brain, which ultimately results in the neuropathological changes associated with the PrP prion diseases-namely, spongiform (vacuolar) de- generation of the brain parenchyma, cerebral deposition of aggregated and misfolded PrP species, neuronal loss, and highly elevated levels of reactive astrocytic gliosis. The self-propagating nature of $\mathrm{PrP}^{\mathrm{Sc}}$ underlies the infectious nature of the human PrP prion disorders, many of which have been successfully transmitted to primates and laboratory rodents.

$\operatorname{PrP}^{\mathrm{C}}$ is a neuronal glycoprotein that is anchored to the outer leaflet of the plasma membrane by virtue of a glycophosphatidylinositol (GPI) anchor. Human (Hu) PrP is initially synthesized as a 253-residue precursor protein that contains an $\mathrm{N}$-terminal signal peptide that directs the protein to the secretory pathway and a C-terminal signal sequence that is replaced by

Editor: Stanley B. Prusiner

Additional Perspectives on Prion Diseases available at www.perspectivesinmedicine.org

Copyright (C) 2017 Cold Spring Harbor Laboratory Press; all rights reserved; doi: 10.1101/cshperspect.a027151

Cite this article as Cold Spring Harb Perspect Med 2017;7:a027151 
the GPI anchor. The mature, processed form of HuPrP consists of residues 23-231 and folds into a structure consisting of two domains: an $\alpha$-helical C-terminal domain and a flexibly disordered N-terminal domain (Zahn et al. 2000), which contains a series of five octapeptide repeats. Whereas $\operatorname{PrP}^{\mathrm{C}}$ is completely digested by proteases such as proteinase $\mathrm{K}(\mathrm{PK}), \mathrm{PrP}^{\mathrm{Sc}}$ is partially resistant. PK-resistant $\operatorname{PrP}^{\mathrm{Sc}}$ species of varying sizes were found in the vast majority of PrP prion disease cases, although PK-sensitive $\mathrm{PrP}^{\mathrm{Sc}}$ isoforms have also been described (Safar et al. 2005).

\section{MUTATIONS IN PrP CAUSE INHERITED PrP PRION DISORDERS}

Approximately $10 \%-15 \%$ of $\operatorname{PrP}$ prion disease cases in humans are heritable and can be classified into three distinct disorders based on their clinical and pathological characteristics: familial Creutzfeldt-Jakob disease (fCJD), Gerstmann-Sträussler-Scheinker disease (GSS), and fatal familial insomnia (FFI). These diseases are caused by autosomal dominant mutations in the PRNP gene, which encodes PrP. In the inherited PrP prion disorders, mutations in PrP are thought to either directly promote the spontaneous misfolding of $\mathrm{PrP}^{\mathrm{C}}$ into $\operatorname{PrP}^{\mathrm{Sc}}$ or to stabilize $\operatorname{PrP}^{\mathrm{Sc}}$ once it is formed. A large spectrum of PrP mutations has been identified in patients with genetic prion disease (Fig. 1). Disease-causing mutations occur throughout the mature, processed form of the protein and can be broken down into three categories: missense mutations; nonsense mutations that result in the production of truncated, GPI-anchorless PrP species; and mutations that increase or decrease the quantity of octapeptide repeats within the N-terminal domain. A common polymorphism also exists in HuPrP at codon 129, where either a methionine $(\mathrm{M})$ or valine $(\mathrm{V})$ residue can be present (Owen et al. 1990).

Like sporadic CJD, fCJD is a rapidly progressive dementia. Mutations that cause fCJD are preferentially located within the $\alpha$-helical C-terminal domain of $\operatorname{PrP}$ (Fig. 1), suggesting that they may act by destabilizing the structure of $\mathrm{PrP}^{\mathrm{C}}$. Octapeptide repeat insertion (OPRI) and octapeptide repeat deletion (OPRD) mutations also cause fCJD. It should be noted that some of the putative fCJD-causing mutations depicted in Figure 1 have only been identified in a small number of patients, raising the possibility that they may constitute rare polymorphic variants identified by chance in patients with sporadic CJD. The neuropathological hallmarks of fCJD are cerebral spongiform degeneration and $\operatorname{PrP}^{\mathrm{Sc}}$ deposits that do not typically contain PrP amyloid. "Stereotypical," variably glycosylated, and N-terminally truncated PK-resistant PrP species that are $\sim 19-30 \mathrm{kDa}$ in size, which are sometimes referred to as $\operatorname{PrP} 27-30$, are found in the brains of fCJD patients.

Compared to fCJD, GSS is a more slowly progressive disease, and patients tend to exhibit more cerebellar symptoms such as ataxia. GSScausing mutations are located throughout the PrP sequence (Fig. 1). Although OPRI mutations cause both fCJD and GSS, longer insertions are typically associated with a GSS phenotype, whereas shorter insertions commonly result in a CJD phenotype. Truncation mutations that cause the production of GPI-anchorless PrP isoforms also cause GSS; interestingly, many of these cases have extensive deposition of $\operatorname{PrP}$ species surrounding blood vessels in the brain (cerebral amyloid angiopathy). The brains of GSS patients typically contain minimal spongiform degeneration but abundant PrP-containing amyloid plaques. The PK-resistant PrP species in GSS patients are usually both $\mathrm{N}$ - and C-terminally truncated and smaller in size, with molecular weights ranging from 7 to $11 \mathrm{kDa}$, than those observed in FCJD patients.

The symptoms of FFI include a progressive insomnia with hallucinations and, ultimately, dementia. A single mutation in $\operatorname{PrP}(\mathrm{D} 178 \mathrm{~N})$ is known to cause FFI. However, FFI only manifests when the mutation is in cis to methionine at polymorphic codon 129; when the D178N mutation occurs in conjunction with valine at codon 129, an fCJD phenotype is present. Pathology in FFI patients is normally restricted to the thalamus, where spongiosis and extensive neuronal loss are apparent. In cases with longer disease duration, cortical pathology is also observed. The brains of FFI patients exhibit low, 

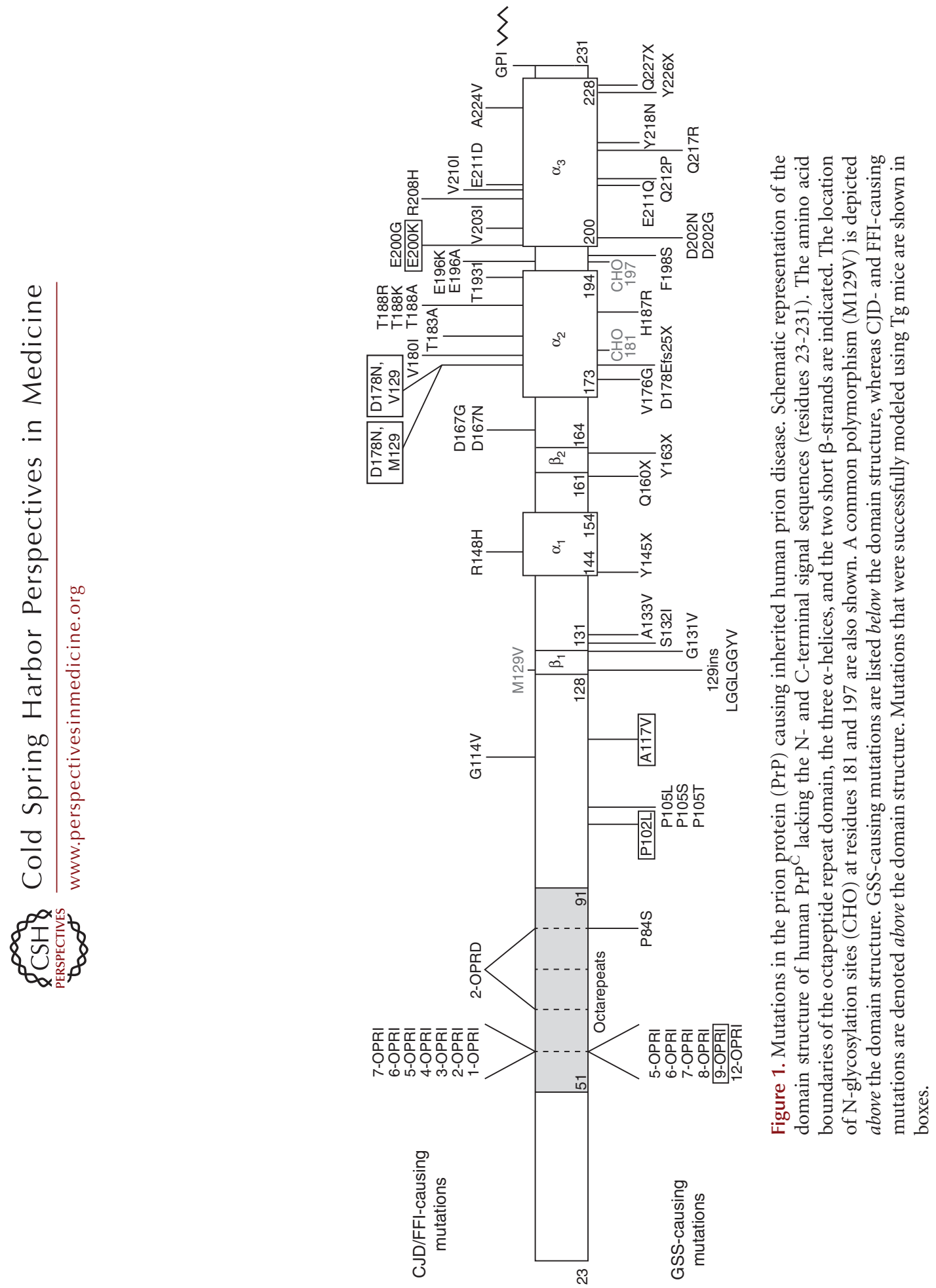
but detectable, levels of "stereotypical" PK-resistant $\operatorname{PrP}^{\mathrm{Sc}}(\operatorname{PrP} 27-30)$.

\section{DESIGNING MOUSE MODELS OF INHERITED PrP PRION DISORDERS}

The discovery that mutations in HuPrP cause inherited PrP prion disorders prompted the investigation of whether animal models of these diseases could be generated by the targeted expression of mutant PrP in the brain. Two general strategies were used when trying to generate mouse models of the inherited PrP prion diseases: transgenic ( $\mathrm{Tg}$ ) mice and knock-in mice. In knock-in mouse models, the endogenous wild-type (WT) mouse PrP locus is replaced with a mutant version via gene targeting (homologous recombination) in embryonic stem cells. Knock-in mice express mutant $\mathrm{PrP}$ at physiological levels under the control of their endogenous regulatory elements, which should ensure the correct spatiotemporal expression pattern. In Tg models, fertilized mouse embryos are microinjected with DNA encoding a transgene cassette that drives expression of mutant PrP in the brain. In all Tg mouse models generated to date, Syrian hamster or mouse PrP promoter elements were used to specify the neuronal expression of mutant PrP. In Tg models, multiple copies of the transgene cassette are typically inserted into the mouse genome, resulting in overexpression of mutant PrP. This has the advantage that disease phenotypes can be obtained more rapidly than in knock-in models. However, integration artifacts can occur following the random insertion of transgenes into the genome, and high levels of even WT PrP overexpression can elicit non-prion-disease-specific pathology (Westaway et al. 1994).

Another consideration is the PrP sequence used as the backbone for the disease-causing mutation. Successful Tg models of the inherited $\operatorname{PrP}$ prion disorders were generated using mouse (Mo) PrP or chimeric $\mathrm{Mo} / \mathrm{Hu} \mathrm{PrP}$ as the starting point. Interestingly, attempts to generate Tg models using mutant $\mathrm{HuPrP}$ have failed, suggesting that $\mathrm{HuPrP}$ is less prone to misfolding than MoPrP or that interactions between MoPrP and other mouse-specific factors are important for the generation of prions. Recently, Tg models were generated using bank vole (BV) PrP. Bank voles (Myodes glareolus) are highly susceptible to human prions, and BVPrP is prone to misfolding spontaneously or upon exposure to prions from many different species (Nonno et al. 2006; Watts et al. 2012, 2014; Orrú et al. 2015).

\section{MOUSE MODELS OF GSS}

The greatest success in modeling inherited PrP prion disorders in mice has been achieved with GSS-causing mutations (Table 1). Expression of PrP containing P102L, A117V, 9-OPRI, or GPIanchorless mutations in the brains of $\mathrm{Tg}$ mice has resulted in a spontaneous neurodegenerative disease phenotype with accompanying GSSspecific neuropathological changes, and in some instances, the generation of small GSSlike PK-resistant PrP fragments.

\section{P102L}

The first inherited prion disease mutation to be successfully modeled using Tg mice was P102L, which is the most common cause of GSS (Hsiao et al. 1989). Tg174 mice overexpressing MoPrP with the mouse equivalent of the mutation (P101L) developed signs of spontaneous neurological illness, including ataxia and rigidity, with a mean age of onset of $\sim 200 \mathrm{~d}$ (Hsiao et al. 1990). The brains of spontaneously ill mice exhibited the hallmark neuropathological changes observed in GSS patients, including spongiform degeneration, PrP-containing amyloid plaques, and reactive astrocytic gliosis (Hsiao et al. 1989, 1994), but did not contain any highly PK-resistant PrP (i.e., resistant to degradation by a PK concentration of $20 \mu \mathrm{g} / \mathrm{mL}$ or higher). However, it was subsequently determined that diseasespecific PrP conformers could be detected in the brains of spontaneously ill mice by digestion with $\mathrm{PK}$ at $4^{\circ} \mathrm{C}$ ("cold PK") followed by precipitation with phosphotungstic acid (PTA) (Tremblay et al. 2004; Nazor et al. 2005). Spontaneous disease has been observed in eight independent lines of $\mathrm{Tg}$ mice overexpressing $\operatorname{MoPrP}(\mathrm{P} 101 \mathrm{~L})$ at levels at least three times higher than those 

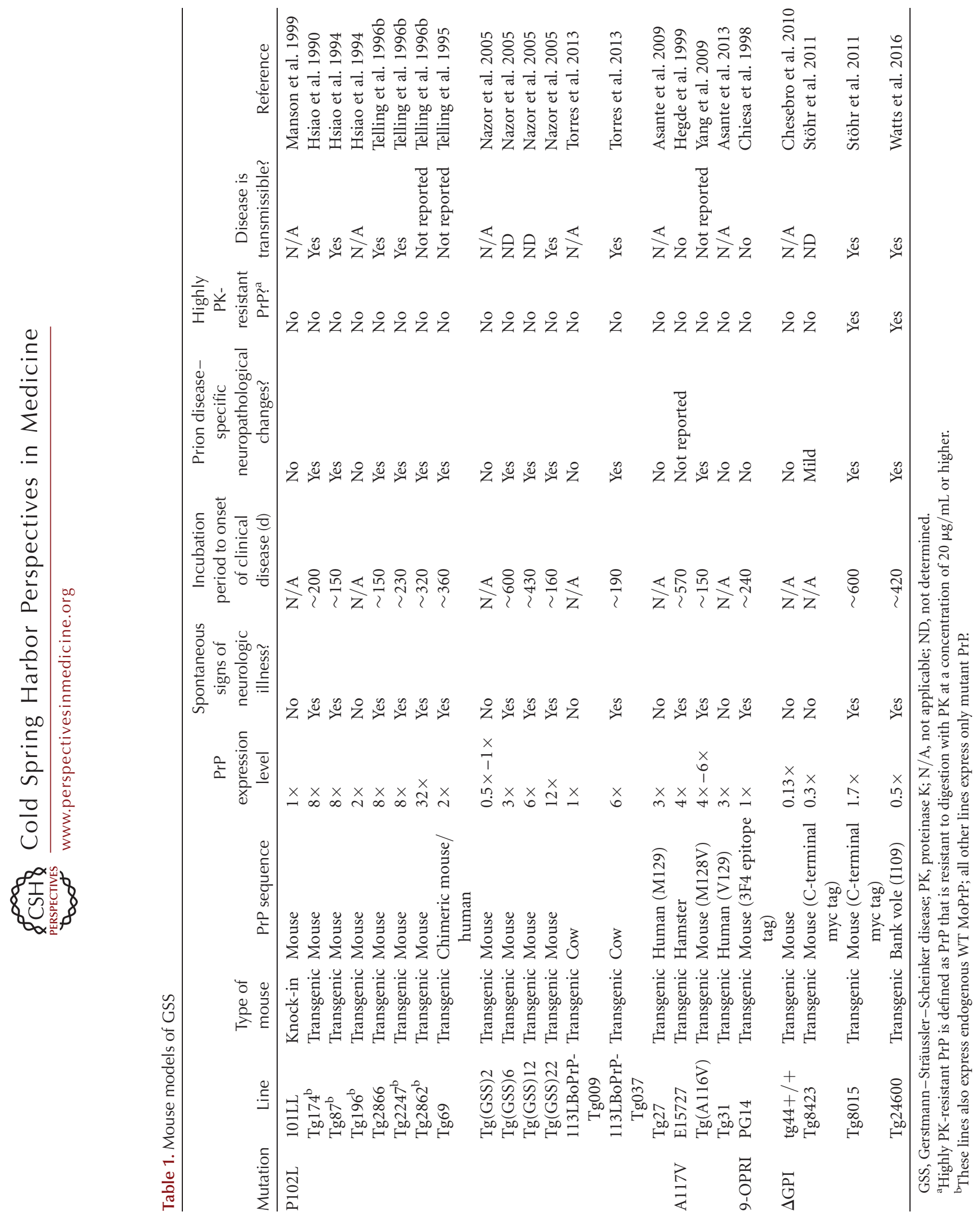
found in WT mice, with mean incubation periods ranging from 150 to $600 \mathrm{~d}$ (Table 1 ) (Hsiao et al. 1994; Telling et al. 1996b; Nazor et al. 2005). Removing the expression of endogenous WT MoPrP both accelerated and unified the disease incubation period in $\mathrm{Tg}$ mice expressing $\operatorname{MoPrP}(\mathrm{P} 101 \mathrm{~L})$ (Telling et al. 1996b), suggesting that the presence of WT PrP can hinder the misfolding of mutant PrP or delay disease progression.

Tg mice expressing $\operatorname{MoPrP}(\mathrm{P} 101 \mathrm{~L})$ at low levels (i.e., $0.5 \times-2 \times$ ) and knock-in mice expressing physiological levels of $\operatorname{MoPrP}(\mathrm{P} 101 \mathrm{~L})$ did not develop spontaneous disease (Hsiao et al. 1994; Manson et al. 1999; Nazor et al. 2005), likely because the disease incubation period exceeds the normal life span of a mouse. Similarly, Tg mice expressing the bovine PrP equivalent of the P102L mutation (P113L) at $1 \times$ levels did not develop a spontaneous illness, whereas mice expressing the mutant protein at $8 \times$ levels developed spontaneous disease in $<200$ d (Torres et al. 2013). Interestingly, Tg mice expressing human $\mathrm{PrP}(\mathrm{HuPrP})$ containing the P102L mutation at $3 \times$ levels failed to develop a spontaneous neurodegenerative illness (Asante et al. 2009), potentially suggesting that elements within the sequence of HuPrP may restrict the spontaneous formation of prions.

Brain homogenates from spontaneously ill $\mathrm{Tg}$ mice expressing high levels of MoPrP (P101L) are capable of transmitting disease to Tg196 mice, which express low levels of $\operatorname{MoPrP}(\mathrm{P} 101 \mathrm{~L})$, indicating that the misfolded PrP conformers in the brains of spontaneously ill mice are infectious (Hsiao et al. 1994; Telling et al. 1996b; Tremblay et al. 2004). In contrast, no disease transmission was observed when samples from spontaneously sick mice were inoculated into non-Tg mice or Tg mice overexpressing WT MoPrP (Hsiao et al. 1994; Telling et al. 1996b; Tremblay et al. 2004), whereas only nine of 348 inoculated hamsters developed disease (Hsiao et al. 1994). One interpretation is that the P101L mutation creates a barrier that hinders the transmission of the spontaneously formed prions to animals expressing WT MoPrP. Another possible interpretation is that the misfolded $\operatorname{MoPrP}(\mathrm{P} 101 \mathrm{~L})$ conformers are only capable of accelerating disease kinetics in mice that are inherently prone to developing spontaneous disease, as opposed to the true generation of prion infectivity. This idea is supported by two observations: (1) A small proportion of Tg196 mice develop a late-onset spontaneous disease (Kaneko et al. 2000); and (2) no disease transmission was observed following inoculation of Tg mice expressing $\mathrm{MoPrP}(\mathrm{P} 101 \mathrm{~L})$ at $0.5 \times-1 \times$ levels (which do not develop lateonset spontaneous disease) with brain homogenate from spontaneously ill Tg mice expressing higher levels of the protein (Nazor et al. 2005). However, it should be noted that not all cases of P102L GSS are transmissible (Tateishi 1996).

\section{A117V}

The A117V mutation, which occurs within the hydrophobic tract region of PrP, is another common cause of GSS (Tateishi et al. 1990; Hsiao et al. 1991). This mutation has been shown to increase the levels of transmembrane topological variants of $\operatorname{PrP}$ (Hegde et al. 1998). Tg mice overexpressing hamster $\operatorname{PrP}$ containing the A117V mutation at $4 \times$ levels developed a lateonset spontaneous neurodegenerative illness with an incubation period of $\sim 570 \mathrm{~d}$ (Table 1) (Hegde et al. 1999). Similarly, Tg mice expressing MoPrP with the mouse equivalent of the mutation (A116V) with fourfold to sixfold overexpression developed spontaneous disease in only $150 \mathrm{~d}$ (Yang et al. 2009). However, no spontaneous disease was observed in $\mathrm{Tg}$ mice expressing A117V-mutant HuPrP with threefold PrP overexpression (Asante et al. 2013). The brains of spontaneously ill A116V-mutant MoPrP mice exhibited prion disease-specific neuropathology, including mild vacuolation and $\mathrm{PrP}$ plaques that were most prominent in the cerebellar cortex (Yang et al. 2009). Although levels of detergent-insoluble $\operatorname{PrP}$ were higher in mice expressing $\operatorname{MoPrP}(\mathrm{A} 116 \mathrm{~V})$ (Yang et al. 2009), no highly PK-resistant PrP species were observed in any of the lines. Transmissibility of the spontaneous disease has not yet been demonstrated, although it should be noted that the transmissibility of GSS cases with the A117V mutation has only recently 
been demonstrated using $\mathrm{Tg}$ mice expressing $\operatorname{HuPrP}(\mathrm{A} 117 \mathrm{~V})$ and only after long incubation periods (Asante et al. 2013).

\section{9-OPRI}

Two families presenting with GSS and a nineoctapeptide repeat insertion (9-OPRI) within the N-terminal domain of PrP have been described (Owen et al. 1992; Krasemann et al. 1995). Tg mice expressing physiological levels of MoPrP with the 9-OPRI mutation have been generated (Chiesa et al. 1998). These mice, termed PG14, develop spontaneous signs of neurological illness (such as ataxia) with a mean onset of $\sim 240 \mathrm{~d}$, and the incubation period is not strongly modulated by the presence or absence of endogenous WT MoPrP (Chiesa et al. 2000). The principal neuropathological finding in spontaneously ill PG14 mice is loss of granule cells within the cerebellum, as well as some accompanying "synaptic-like" $\mathrm{PrP}$ deposition in the molecular layer and reactive astrocytic gliosis (Chiesa et al. 1998). No obvious spongiosis is present in the brains of PG14 mice. Although the mutant PrP in PG14 mice is detergent-insoluble and mildly PK-resistant (Chiesa et al. 1998, 2000), no disease transmission was observed when brain extracts from spontaneously ill mice were injected into nonTg mice, Tg mice expressing WT MoPrP, or Tg mice expressing 9-OPRI-mutant MoPrP at lower levels that do not develop spontaneous disease (Chiesa et al. 2003). These results imply that prions are not formed in the brains of PG14 mice, and the spontaneous disease may be better characterized as a "PrP proteinopathy."

\section{GPI-Anchorless PrP}

Two GSS cases were identified with either Y226X or Q227X mutations in PRNP (Jansen et al. 2010). These mutations result in the production of nearly full-length GPI-anchorless PrP (“ $\Delta \mathrm{GPI}$ ”) species and cause a profound $\mathrm{PrP}$ amyloidosis in the brain. In earlier studies, Tg mice expressing GPI-anchorless MoPrP were generated to examine the necessity of the PrP GPI anchor for the propagation of prions (Chesebro et al. 2005). These mice express very low levels of $\operatorname{PrP}(\Delta \mathrm{GPI})$ and did not exhibit any spontaneous signs of neurological illness (Chesebro et al. 2010). Later, Tg mice expressing GPI-anchorless MoPrPat higher levels ( 1.7-fold higher than PrP levels in non-Tg mice) were generated (Stöhr et al. 2011). Approximately 50\% of these mice, termed Tg8015, developed a late-onset spontaneous neurological disorder (Table 1). The brains of spontaneously ill Tg8015 mice exhibited a large number of PrP-amyloid deposits, and a highly PK-resistant PrP fragment of $\sim 10 \mathrm{kDa}$, similar to fragments found in GSS cases, was observed in brain extracts from sick mice. Moreover, brain homogenates from spontaneously ill Tg8015 mice accelerated disease when inoculated into young Tg8015 mice and transmitted disease to $\mathrm{Tg}$ mice overexpressing WT MoPrP, confirming the spontaneous generation of GPI-anchorless prions (Stöhr et al. 2011).

Because Tg mice expressing membrane-anchored, WT bank vole PrP (BVPrP) containing isoleucine at polymorphic codon 109 (I109) developed a spontaneous prion disease (Watts et al. 2012), Tg mice expressing GPI-anchorless BVPrP(I109) were also generated. All of these mice, termed Tg24600, developed spontaneous disease, with a mean age of onset of $\sim 420 \mathrm{~d}$ (Table 1), despite the fact that PrP levels were about three times lower than in the brains of Tg8015 mice (Watts et al. 2016). The brains of spontaneously ill Tg24600 mice contained abundant PrP deposits (including PrP-containing amyloid plaques) (Fig. 2) and an $\sim 8$-kDa highly PK-resistant PrP fragment. Moreover, brain extracts from sick mice accelerated disease when inoculated into young $\operatorname{Tg} 24600$ mice or Tg mice expressing WT BVPrP(I109). Thus, Tg mice expressing GPI-anchorless MoPrP or BVPrP recapitulate the pathological and biochemical hallmarks of the associated GSS cases, suggesting that they may be excellent models for testing candidate GSS therapeutics.

\section{Y145X}

A nonsense mutation at codon 145 of $\operatorname{PrP}$ (Y145X) causes vascular and parenchymal dep- 
J.C. Watts and S.B. Prusiner

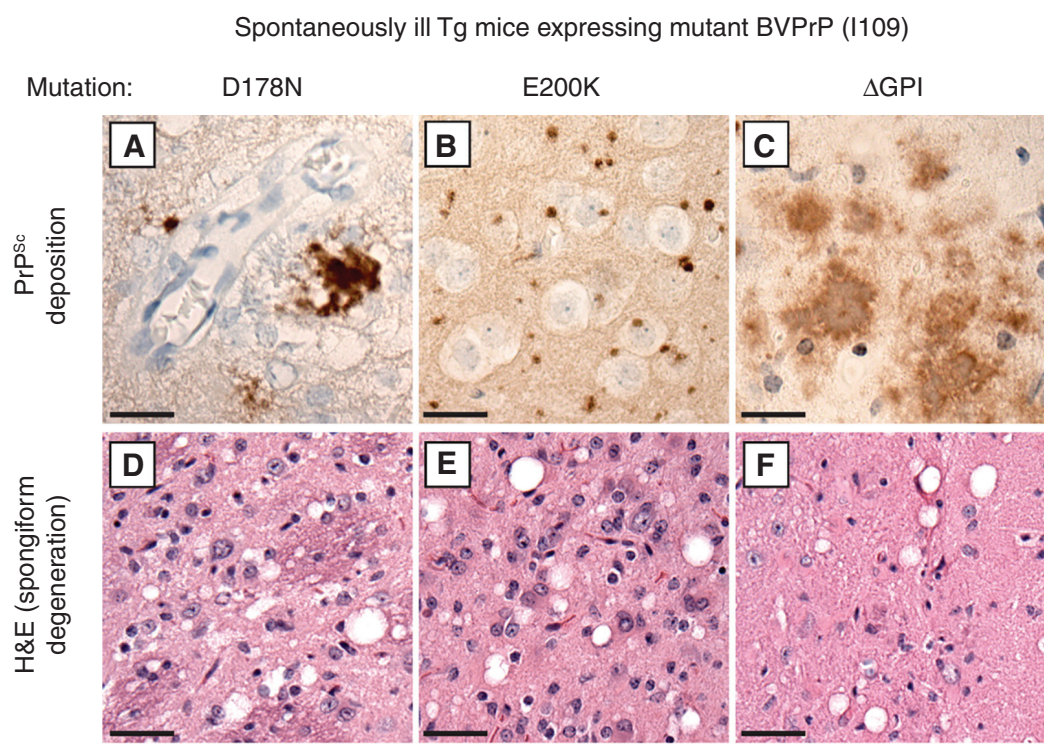

Figure 2. Prion disease-specific neuropathology in Tg mice expressing mutant bank vole $\operatorname{PrP} .(A-C) \operatorname{PrP}^{\mathrm{Sc}}$ deposition, as determined by immunohistochemistry with the antibody HuM-P, and $(D-F)$ spongiform degeneration, as revealed by hematoxylin and eosin $(\mathrm{H} \& \mathrm{E})$ staining, are apparent in brain sections prepared from spontaneously ill Tg mice expressing D178N-mutant $(A, D)$, E200K-mutant $(B, E)$, or $\Delta$ GPI-mutant $(C, F)$ $\mathrm{BVPrP}(\mathrm{I} 109)$. Unique patterns of $\operatorname{PrP}^{\mathrm{Sc}}$ deposition were observed with each mutation: clustered coarse deposits with D178N, small round deposits with E200K, and "plaque-like" deposits with $\Delta$ GPI. Scale bars, $20 \mu \mathrm{m}(A-C)$; $40 \mu \mathrm{m}(D-F)$.

osition of PrP amyloid in GSS patients (Kitamoto et al. 1993; Ghetti et al. 1996). Attempts to model this disease using Tg mice have been unsuccessful: Two independent lines of Tg mice expressing $\mathrm{MoPrP}$ with the equivalent mutation (Y144X) did not exhibit any mutant protein expression and did not develop spontaneous disease (Fischer et al. 1996; Muramoto et al. 1997).

\section{MOUSE MODELS OF FFI}

Several attempts were made to model FFI using genetically modified mice (Table 2 ). The first attempt used knock-in mice (ki-3F4-FFI) in which the WT MoPrP open reading frame was replaced with a mutant allele carrying the D177N mutation, which is the mouse PrP equivalent of the D178N mutation in FFI patients (Jackson et al. 2009), as well as a tworesidue substitution to confer immunoreactivity to the 3F4 antibody. Some of the ki-3F4-FFI mice developed late-onset neurological illness with accompanying neuronal loss and gliosis in the thalamus, which is the principal target area in FFI patients, although no highly PK-resistant PrP species and no PrP deposits were observed in the brain (Jackson et al. 2009). Inoculation of Tga20 mice overexpressing WT MoPrP or knock-in mice expressing 3F4-tagged $\mathrm{MoPrP}$ with brain extracts from spontaneously sick ki-3F4-FFI mice resulted in disease transmission, confirming the generation of prion infectivity.

Tg mice expressing D177N-mutant MoPrP have also been created. FFI-26 mice, which express mutant $\operatorname{PrP}$ at $2 \times$ levels, developed a progressive neurological disease at $\sim 200 \mathrm{~d}$ of age that was characterized by ataxia and kyphosis (Bouybayoune et al. 2015). Tg mice expressing D177N-mutant PrP at $1 \times$ also developed spontaneous disease, whereas mice with $0.5 \times$ expression did not. In FFI-26 mice, co-expression of WT endogenous MoPrP had no effect on disease onset. Mild thalamic and cerebellar atrophy was observed in the brains of aged FFI- 
Mouse Models of Inherited PrP Prion Diseases
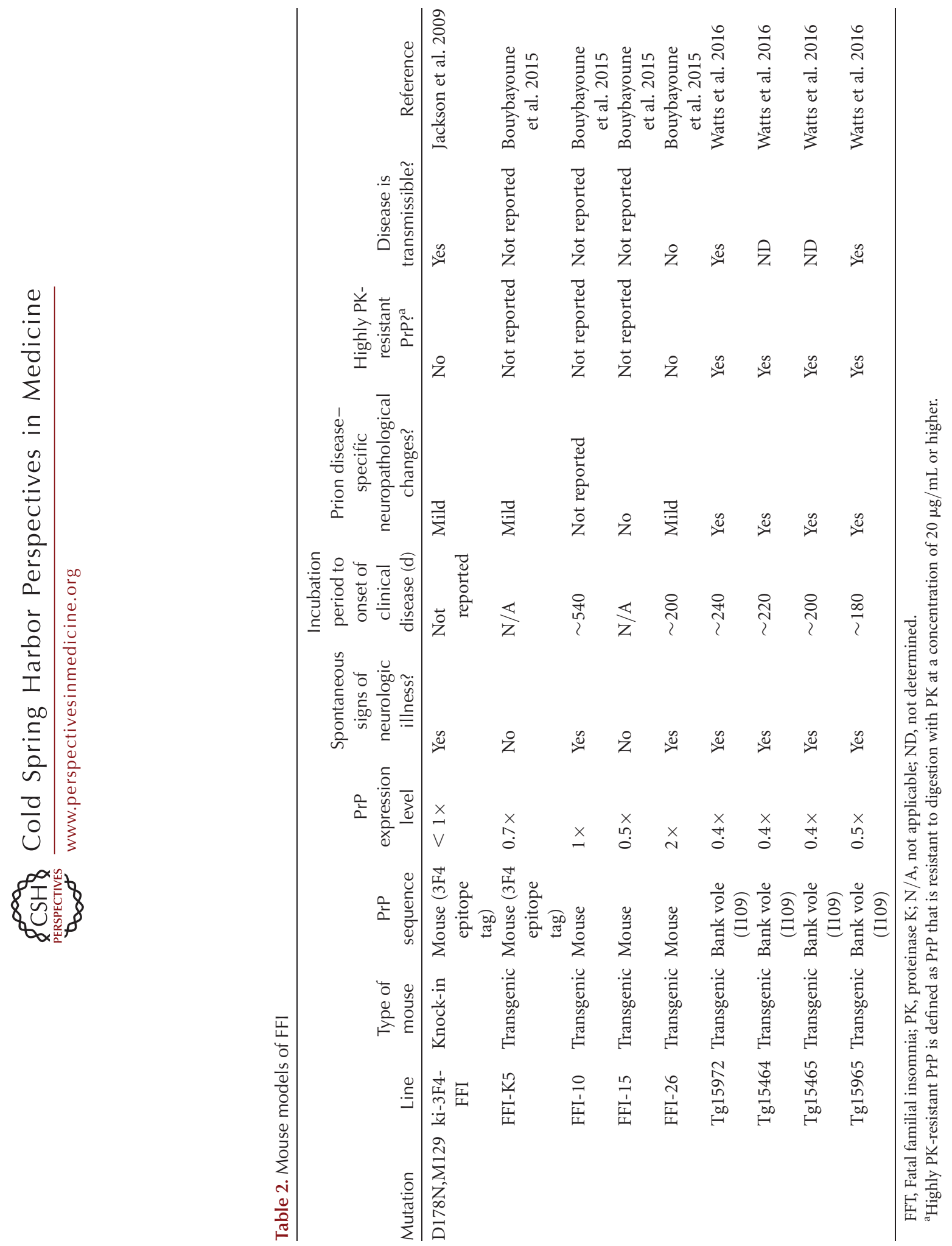
26 mice, as was some "synaptic-like" $\operatorname{PrP}$ deposition, but no spongiform degeneration was detected. The D177N-mutant PrP in FFI-26 mice exhibited increased detergent insolubility and PK resistance compared to WT PrP, but no highly PK-resistant PrP species were present. No transmission was observed following inoculation of non-Tg or Tga 20 mice with brain homogenates from diseased FFI-26 mice, arguing that the pathogenic changes observed in FFI-26 mice are not related to the generation of prion infectivity (Bouybayoune et al. 2015).

Four independent lines of Tg mice expressing $\mathrm{BVPrP}(\mathrm{I} 109)$ containing the $\mathrm{D} 178 \mathrm{~N}$ mutation at low levels $(0.4 \times-0.5 \times)$ developed a highly penetrant spontaneous neurological illness with incubation periods ranging from $\sim 180$ to $\sim 240 \mathrm{~d}$ (Table 2 ) (Watts et al. 2016). The brains of spontaneously ill mice exhibited spongiform degeneration, reactive astrocytic gliosis, and clustered coarse PrP deposits similar to those that have been observed in some FFI patients (Almer et al. 1999). Moreover, a highly PK-resistant $\operatorname{PrP}$ species with a molecular weight of $\sim 8 \mathrm{kDa}$ was found in symptomatic mice but not in young, asymptomatic animals. The disease could be transmitted to Tg mice expressing WT BVPrP(I109) and to Tg4053 mice overexpressing WT MoPrP.

Both the ki-3F4-FFI and FFI-26 models also display behavioral abnormalities. Using automated mouse behavioral analysis, it was determined that ki-3F4-FFI mice exhibit increased sleep interruption as measured by twitching during rest and extended periods of inactivity, possibly from a lack of uninterrupted sleep (Jackson et al. 2009). Moreover, compared to controls, FFI-26 mice exhibited numerous sleep abnormalities such as defective circadian organization, increased disruptions to sleep continuity, and abnormal entry into REM sleep (Bouybayoune et al. 2015). Collectively, these studies indicate that mouse models of FFI may recapitulate some of the key clinical hallmarks of the disease in addition to pathological markers. However, none of the FFI models developed to date produce $\mathrm{PrP} 27-30$, which is found in all patients with FFI.

\section{MOUSE MODELS OF fCJD}

Of the large number of purported fCJD-causing mutations in PRNP (Fig. 1), only two (E200K and $\mathrm{D} 178 \mathrm{~N}$ ) have resulted in clear spontaneous disease with prion disease-specific neuropathological changes when inserted into PrP and expressed in the brains of Tg mice. Although highly PK-resistant PrP species were found in the brains of some of these lines, they do not resemble those present in corresponding fCJD patients.

\section{E200K}

Early attempts to model fCJD caused by the E200K mutation were unsuccessful. Despite overexpressing the MoPrP equivalent of the mutation (E199K) at $8 \times$ levels, no spontaneous disease was observed in Tg5182 mice, although it should be noted that endogenous WT MoPrP was also present in these mice, which may have restricted the formation of prions (Telling et al. 1996b). Furthermore, Tg mice overexpressing $\mathrm{HuPrP}$ containing the E200K mutation at $3 \times$ levels showed no signs of spontaneous neurological illness or prion disease-specific neuropathological changes (Asante et al. 2009).

Although $\mathrm{Tg}$ mice expressing MoPrP (E199K) did not develop spontaneous disease, $\mathrm{Tg}$ mice expressing a chimeric $\mathrm{Mo} / \mathrm{Hu} \mathrm{PrP}$ containing the E199K mutation at $2 \times$ levels exhibited hind-limb paralysis and kyphosis beginning at $\sim 200 \mathrm{~d}$ of age and eventually died around $\sim 365 \mathrm{~d}$ (Friedman-Levi et al. 2011). Co-expression of endogenous WT MoPrP did not have a major effect on disease manifestation (Friedman-Levi et al. 2013). Some PrP deposition was apparent throughout the brain, but only minimal spongiform degeneration was observed (Friedman-Levi et al. 2011). Some atypical PK-resistant $\mathrm{PrP}$ species were found in the brains of sick mice (FriedmanLevi et al. 2011, 2013). Inoculation of non-Tg mice with brain homogenates from spontaneously ill $\mathrm{Tg}$ mice resulted in some instances of disease transmission, but the transmission efficiency was highly variable (Friedman-Levi et al. 2011). 
Knock-in mice expressing E199K-mutant MoPrP (also containing the 3F4 epitope tag) at physiological levels exhibited some clinical abnormalities, such as reduced performance on the rotarod test and decreased burrowing behavior, but were not reported to develop profound clinical signs of a neurodegenerative disease (Jackson et al. 2013). In contrast to the ki3F4-FFI mice, the ki-3F4-CJD mice exhibited clear spongiosis and punctate PrP deposits in the brain with aging. Some mildly PK-resistant $\operatorname{PrP}$ was present in ki-3F4-CJD mice, but the highly PK-resistant $\operatorname{PrP}$ species observed in CJD(E200K) patients was not observed. Passage of brain extracts from ki-3F4-CJD mice into $\mathrm{Tg} a 20$ mice or non-Tg mice resulted in efficient disease transmission, confirming that prions were formed spontaneously in the brains of these knock-in mice.

Like with the D178N mutation, addition of the $\mathrm{E} 200 \mathrm{~K}$ mutation to $\mathrm{BVPrP}(\mathrm{I} 109)$ reduced the amount of protein overexpression required to produce spontaneous disease. In fact, spontaneous disease was observed in all of the mice generated, including mice that expressed physiological levels of mutant PrP (Table 3) (Watts et al. 2016). Like the ki-3F4-CJD mice, Tg mice expressing E200K-mutant BVPrP(I109) exhibited small, rounded PrP aggregates in the brain as well as spongiform degeneration. A highly PK-resistant PrP fragment of $\sim 8 \mathrm{kDa}$ was observed in the brains of spontaneously ill animals and also upon transmission of the disease to $\mathrm{Tg}$ mice expressing WT BVPrP(I109) or MoPrP. In both the knock-in and BVPrP(I109) Tg models, FFI- and CJD-causing mutations caused distinct spontaneous pathologies, as well as unique pathologies, following transmission, providing evidence that the D178N and E200K mutations cause the formation of different prion strains.

\section{D178N}

Tg mice expressing MoPrP containing the mouse equivalent of the $\mathrm{D} 178 \mathrm{~N}$ mutation (D177N) along with an M128V substitution were generated to model inherited CJD cases caused by the PRNP D178N,V129 haplotype. In homozygous " $\mathrm{Tg}(\mathrm{CJD})$ " mice with approxi- mately twofold overexpression of D177N-mutant PrP, signs of spontaneous neurological illness such as ataxia, kyphosis, and foot clasping began to appear at $\sim 150 \mathrm{~d}$ of age and ultimately resulted in death of the mice by $\sim 300 \mathrm{~d}$ of age (Dossena et al. 2008). Detergent-insoluble and mildly PK-resistant PrP species were observed in $\operatorname{Tg}(\mathrm{CJD})$ mice and were accompanied by some PrP deposition and reactive astrocytic gliosis in the brain. However, no spongiform degeneration was observed. Brain extracts from spontaneously ill $\mathrm{Tg}(\mathrm{CJD})$ mice did not transmit disease to non-Tg mice, $\mathrm{Tg}$ mice overexpressing WT MoPrP, or to Tg mice expressing lower levels of D177N-mutant MoPrP(V128) (Bouybayoune et al. 2015).

\section{T183A}

A T183A mutation in PRNP has been found in multiple individuals with CJD (Nitrini et al. 1997; Grasbon-Frodl et al. 2004). This mutation abolishes the first glycosylation site in $\operatorname{PrP}$ by altering the consensus sequence for $\mathrm{N}$-glycan attachment. Tg mice expressing Syrian hamster PrP containing the T183A mutation were generated, but these mice did not develop spontaneous disease (DeArmond et al. 1997).

\section{A224V}

A previously unreported A224V mutation was found in cis to valine at codon 129 in a patient with CJD (Watts et al. 2015). Tg mice expressing A224V-mutant $\mathrm{HuPrP}(\mathrm{V} 129)$ at levels up to $\sim 3 \times$ did not develop any spontaneous signs of neurological illness with aging and did not exhibit any detergent-insoluble or PK-resistant PrP species in their brains (Watts et al. 2015).

\section{REMAINING CHALLENGES}

A critical unresolved issue is determining why the brains of spontaneously ill Tg mice expressing PrP with a fCJD- or FFI-causing mutation do not exhibit the principal biochemical hallmark of these diseases. None of the mouse models of inherited PrP prion disorders created to date develop "stereotypical," highly PK-resis- 
J.C. Watts and S.B. Prusiner
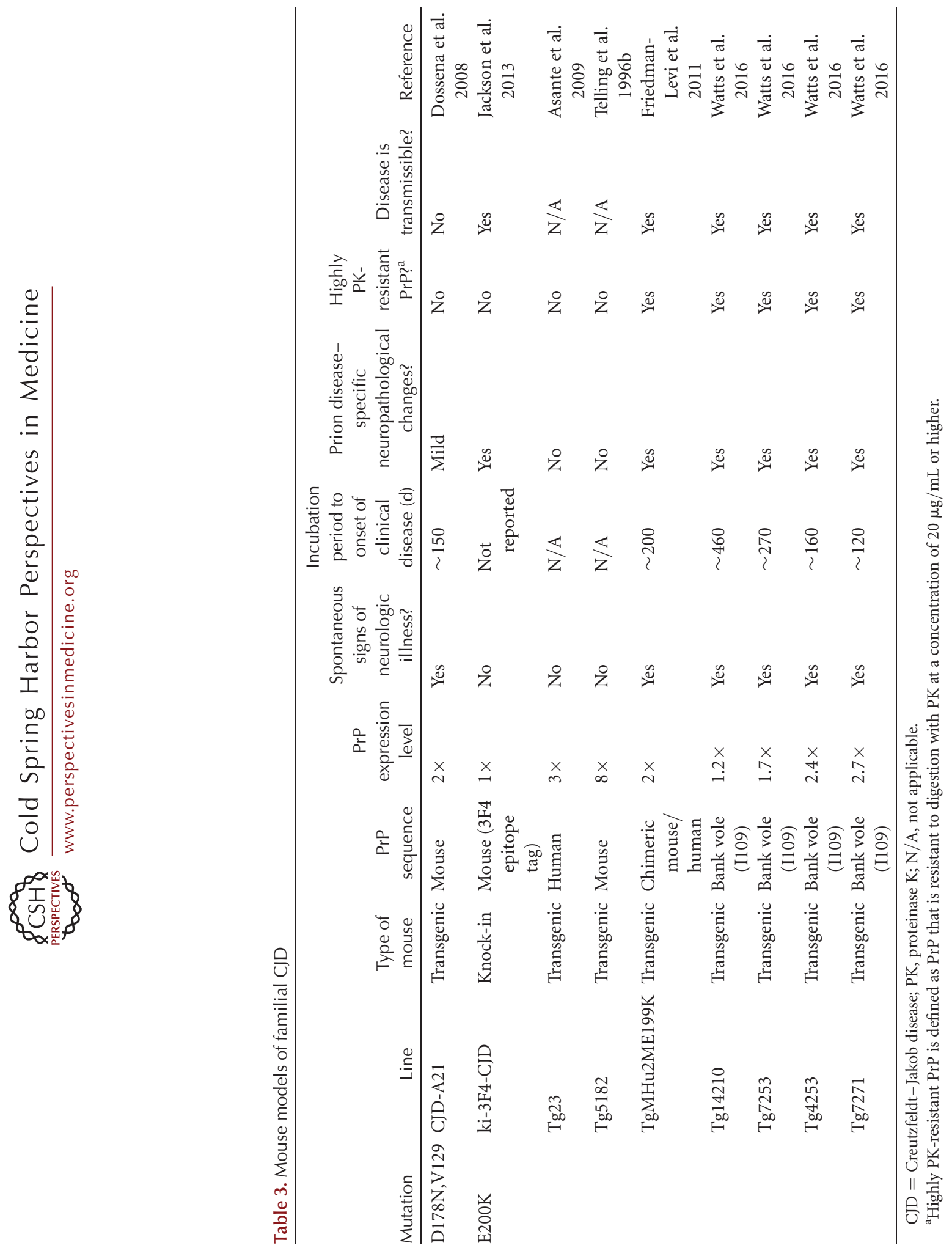
tant PrP species (i.e., PrP27-30) in their brains, despite the presence of obvious prion diseasespecific neuropathological changes. The reason behind this conundrum is unclear, but possibilities include inherent differences between the brains of mice and humans or the necessity for extended incubation periods to generate PrP27-30 spontaneously, which cannot be achieved within the normal life span of a mouse. Familial CJD and FFI prions have been successfully transmitted to $\mathrm{Tg}$ mice expressing chimeric $\mathrm{Mo} / \mathrm{HuPrP}$, resulting in the presence of fCJD- or FFI-specific PrP27-30 species in the brain (Telling et al. 1995, 1996a). This finding indicates that mice are capable of propagating such PK-resistant PrP species, and their nonexistence in $\mathrm{Tg}$ mouse models may indicate an inability for them to be formed in the absence of a template. For fCJD, only a small subset of mutations were investigated in Tg mice, and it remains possible that investigating additional, perhaps rarer mutations may be necessary for generating a completely faithful model.

Other challenges include successively modeling the selective targeting of certain brain regions and neuronal populations specified by distinct mutations in PRNP and fully recapitulating some of the critical clinical aspects of these disorders. Although some progress has certainly been made in these areas (Jackson et al. 2009; Bouybayoune et al. 2015), it is clear that there is room for the creation of superior models. "Next generation" animal models of the inherited PrP prion disorders may need to take advantage of PrP sequences that are more prone to misfolding (such as BVPrP) or exploit the advantages offered by $\mathrm{Tg}$ rats, which were used to generate a potentially more authentic model of AD (Cohen et al. 2013).

\section{CONCLUDING REMARKS}

Although much progress has been made toward generating accurate mouse models of the inherited $\operatorname{PrP}$ prion disorders, most of the currently available models do not fully recapitulate the entire spectrum of clinical, biochemical, and pathological hallmarks of the corresponding human disease. Development of more transla- tional animal models not only will provide a system for studying the earliest events in prion generation and spread in vivo, but also will create a paradigm for assessing the efficacy of candidate therapeutics designed to interfere with prion formation. Individuals predisposed to developing an inherited PrP prion disorder are likely to benefit the most from the creation of drugs that halt prion formation and/or replication because they can be identified early in life and treatment can commence long before any irreversible neuropathological changes have occurred in the brain. Thus, mouse models of the inherited PrP prion disorders will likely play a critical role in current and future prion disease drug discovery efforts.

\section{ACKNOWLEDGMENTS}

The authors wish to acknowledge support from the Natural Sciences and Engineering Research Council of Canada and the Canadian Foundation for Innovation (J.C.W.), as well as the U.S. National Institutes of Health (AG002132 and AG031220), Daiichi Sankyo, the Glenn Foundation, the Henry M. Jackson Foundation, the Rainwater Charitable Foundation, and the Sherman Fairchild Foundation (S.B.P.).

\section{REFERENCES}

Almer G, Hainfellner JA, Brücke T, Jellinger K, Kleinert R, Bayer G, Windl O, Kretzschmar HA, Hill A, Sidle K, et al. 1999. Fatal familial insomnia: A new Austrian family. Brain 122: $5-16$

Asante EA, Gowland I, Grimshaw A, Linehan JM, Smidak M, Houghton R, Osiguwa O, Tomlinson A, Joiner S, Brandner S, et al. 2009. Absence of spontaneous disease and comparative prion susceptibility of transgenic mice expressing mutant human prion proteins. J Gen Virol 90: 546-558.

Asante EA, Linehan JM, Smidak M, Tomlinson A, Grimshaw A, Jeelani A, Jakubcova T, Hamdan S, Powell C, Brandner S, et al. 2013. Inherited prion disease A117V is not simply a proteinopathy but produces prions transmissible to transgenic mice expressing homologous prion protein. PLoS Pathog 9: e1003643.

Bouybayoune I, Mantovani S, Del Gallo F, Bertani I, Restelli E, Comerio L, Tapella L, Baracchi F, Fernández-Borges N, Mangieri M, et al. 2015. Transgenic fatal familial insomnia mice indicate prion infectivity-independent mechanisms of pathogenesis and phenotypic expression of disease. PLoS Pathog 11: e1004796. 
J.C. Watts and S.B. Prusiner

Chesebro B, Trifilo M, Race R, Meade-White K, Teng C, LaCasse R, Raymond L, Favara C, Baron G, Priola S, et al. 2005. Anchorless prion protein results in infectious amyloid disease without clinical scrapie. Science 308: 1435-1439.

Chesebro B, Race B, Meade-White K, Lacasse R, Race R, Klingeborn M, Striebel J, Dorward D, McGovern G, Jeffrey M. 2010. Fatal transmissible amyloid encephalopathy: A new type of prion disease associated with lack of prion protein membrane anchoring. PLoS Pathog 6: e1000800.

Chiesa R, Piccardo P, Ghetti B, Harris DA. 1998. Neurological illness in transgenic mice expressing a prion protein with an insertional mutation. Neuron 21: 1339-1351.

Chiesa R, Drisaldi B, Quaglio E, Migheli A, Piccardo P, Ghetti B, Harris DA. 2000. Accumulation of proteaseresistant prion protein $(\mathrm{PrP})$ and apoptosis of cerebellar granule cells in transgenic mice expressing a PrP insertional mutation. Proc Natl Acad Sci 97: 5574-5579.

Chiesa R, Piccardo P, Quaglio E, Drisaldi B, Si-Hoe SL, Takao M, Ghetti B, Harris DA. 2003. Molecular distinction between pathogenic and infectious properties of the prion protein. J Virol 77: 7611-7622.

Cohen RM, Rezai-Zadeh K, Weitz TM, Rentsendorj A, Gate D, Spivak I, Bholat Y, Vasilevko V, Glabe CG, Breunig JJ, et al. 2013. A transgenic Alzheimer rat with plaques, tau pathology, behavioral impairment, oligomeric $A \beta$, and frank neuronal loss. J Neurosci 33: 6245-6256.

Colby DW, Prusiner SB. 2011. Prions. Cold Spring Harb Perspect Biol 3: a006833.

DeArmond SJ, Sánchez H, Yehiely F, Qiu Y, Ninchak-Casey A, Daggett V, Camerino AP, Cayetano J, Rogers M, Groth D, et al. 1997. Selective neuronal targeting in prion disease. Neuron 19: 1337-1348.

Dossena S, Imeri L, Mangieri M, Garofoli A, Ferrari L, Senatore A, Restelli E, Balducci C, Fiordaliso F, Salio M, et al. 2008. Mutant prion protein expression causes motor and memory deficits and abnormal sleep patterns in a transgenic mouse model. Neuron 60: 598-609.

Fischer M, Rülicke T, Raeber A, Sailer A, Moser M, Oesch B, Brandner S, Aguzzi A, Weissmann C. 1996. Prion protein $(\mathrm{PrP})$ with amino-proximal deletions restoring susceptibility of PrP knockout mice to scrapie. EMBO J 15: 1255-1264.

Friedman-Levi Y, Meiner Z, Canello T, Frid K, Kovacs GG, Budka H, Avrahami D, Gabizon R. 2011. Fatal prion disease in a mouse model of genetic E200K CreutzfeldtJakob disease. PLoS Pathog 7: e1002350.

Friedman-Levi Y, Mizrahi M, Frid K, Binyamin O, Gabizon R. 2013. $\operatorname{PrP}^{\mathrm{ST}}$, a soluble, protease resistant and truncated $\mathrm{PrP}$ form features in the pathogenesis of a genetic prion disease. PLoS One 8: e69583.

Ghetti B, Piccardo P, Spillantini MG, Ichimiya Y, Porro M, Perini F, Kitamoto T, Tateishi J, Seiler C, Frangione B, et al. 1996. Vascular variant of prion protein cerebral amyloidosis with $\tau$-positive neurofibrillary tangles: The phenotype of the stop codon 145 mutation in PRNP. Proc Natl Acad Sci 93: 744-748.

Grasbon-Frodl E, Lorenz H, Mann U, Nitsch RM, Windl O, Kretzschmar HA. 2004. Loss of glycosylation associated with the T183A mutation in human prion disease. Acta Neuropathol 108: 476-484.
Hegde RS, Mastrianni JA, Scott MR, DeFea KA, Tremblay P, Torchia M, DeArmond SJ, Prusiner SB, Lingappa VR. 1998. A transmembrane form of the prion protein in neurodegenerative disease. Science 279: 827-834.

Hegde RS, Tremblay P, Groth D, Prusiner SB, Lingappa VR. 1999. Transmissible and genetic prion diseases share a common pathway of neurodegeneration. Nature 402: 822-826.

Hsiao K, Baker HF, Crow TJ, Poulter M, Owen F, Terwilliger JD, Westaway D, Ott J, Prusiner SB. 1989. Linkage of a prion protein missense variant to Gerstmann-Sträussler syndrome. Nature 338: 342-345.

Hsiao KK, Scott M, Foster D, Groth DF, DeArmond SJ, Prusiner SB. 1990. Spontaneous neurodegeneration in transgenic mice with mutant prion protein. Science 250: $1587-1590$.

Hsiao KK, Cass C, Schellenberg GD, Bird T, Devine-Gage E, Wisniewski H, Prusiner SB. 1991. A prion protein variant in a family with the telencephalic form of GerstmannSträussler-Scheinker syndrome. Neurology 41: 681-684.

Hsiao KK, Groth D, Scott M, Yang SL, Serban H, Rapp D, Foster D, Torchia M, DeArmond SJ, Prusiner SB. 1994. Serial transmission in rodents of neurodegeneration from transgenic mice expressing mutant prion protein. Proc Natl Acad Sci 91: 9126-9130.

Jackson WS, Borkowski AW, Faas H, Steele AD, King OD, Watson N, Jasanoff A, Lindquist S. 2009. Spontaneous generation of prion infectivity in fatal familial insomnia knockin mice. Neuron 63: 438-450.

Jackson WS, Borkowski AW, Watson NE, King OD, Faas H, Jasanoff A, Lindquist S. 2013. Profoundly different prion diseases in knock-in mice carrying single PrP codon substitutions associated with human diseases. Proc Natl Acad Sci 110: 14759-14764.

Jansen C, Parchi P, Capellari S, Vermeij AJ, Corrado P, Baas F, Strammiello R, van Gool WA, van Swieten JC, Rozemuller AJM. 2010. Prion protein amyloidosis with divergent phenotype associated with two novel nonsense mutations in PRNP. Acta Neuropathol 119: 189-197.

Kaneko K, Ball HL, Wille H, Zhang H, Groth D, Torchia M, Tremblay P, Safar J, Prusiner SB, DeArmond SJ, et al. 2000. A synthetic peptide initiates Gerstmann-Sträussler-Scheinker (GSS) disease in transgenic mice. J Mol Biol 295: 997-1007.

Kitamoto T, Iizuka R, Tateishi J. 1993. An amber mutation of prion protein in Gerstmann-Sträussler syndrome with mutant PrP plaques. Biochem Biophys Res Commun 192: $525-531$.

Krasemann S, Zerr I, Weber T, Poser S, Kretzschmar H, Hunsmann G, Bodemer W. 1995. Prion disease associated with a novel nine octapeptide repeat insertion in the PRNP gene. Brain Res Mol Brain Res 34: 173-176.

Manson JC, Jameison E, Baybutt H, Tuzi NL, Barron R, McConnell I, Somerville R, Ironside J, Will R, Sy MS, et al. 1999. A single amino acid alteration (101L) introduced into murine PrP dramatically alters incubation time of transmissible spongiform encephalopathy. EMBO J 18: 6855-6864.

Muramoto T, DeArmond SJ, Scott M, Telling GC, Cohen FE, Prusiner SB. 1997. Heritable disorder resembling neuronal storage disease in mice expressing prion protein with deletion of an $\alpha$-helix. Nat Med 3: 750-755. 
Nazor KE, Kuhn F, Seward T, Green M, Zwald D, Purro M, Schmid J, Biffiger K, Power AM, Oesch B, et al. 2005. Immunodetection of disease-associated mutant PrP, which accelerates disease in GSS transgenic mice. EMBO J 24: 2472-2480

Nitrini R, Rosemberg S, Passos-Bueno MR, da Silva LS, Lughetti P, Papadopoulos M, Carrilho PM, Caramelli P, Albrecht S, Zatz M, et al. 1997. Familial spongiform encephalopathy associated with a novel prion protein gene mutation. Ann Neurol 42: 138-146.

Nonno R, Di Bari MA, Cardone F, Vaccari G, Fazzi P, Dell'Omo G, Cartoni C, Ingrosso L, Boyle A, Galeno R, et al. 2006. Efficient transmission and characterization of Creutzfeldt-Jakob disease strains in bank voles. PLoS Pathog 2: e12.

Orrú CD, Groveman BR, Raymond LD, Hughson AG, Nonno R, Zou W, Ghetti B, Gambetti P, Caughey B. 2015. Bank vole prion protein as an apparently universal substrate for RT-QuIC-based detection and discrimination of prion strains. PLoS Pathog 11: e1004983.

Owen F, Poulter M, Collinge J, Crow TJ. 1990. Codon 129 changes in the prion protein gene in Caucasians. Am J Hum Genet 46: 1215-1216.

Owen F, Poulter M, Collinge J, Leach M, Lofthouse R, Crow TJ, Harding AE. 1992. A dementing illness associated with a novel insertion in the prion protein gene. Mo Brain Res 13: 155-157.

Safar JG, Geschwind MD, Deering C, Didorenko S, Sattavat M, Sanchez H, Serban A, Vey M, Baron H, Giles K, et al. 2005. Diagnosis of human prion disease. Proc Natl Acad Sci 102: 3501-3506.

Stöhr J, Watts JC, Legname G, Oehler A, Lemus A, Nguyen HOB, Sussman J, Wille H, DeArmond SJ, Prusiner SB, et al. 2011. Spontaneous generation of anchorless prions in transgenic mice. Proc Natl Acad Sci 108: 21223-21228.

Tateishi J. 1996. Transmission of human prion disease to rodents. Semin Virol 7: 175-180.

Tateishi J, Kitamoto T, Doh-ura K, Sakaki Y, Steinmetz G, Tranchant C, Warter JM, Heldt N. 1990. Immunochemical, molecular genetic, and transmission studies on a case of Gerstmann-Sträussler-Scheinker syndrome. Neurology 40: 1578-1581.

Telling GC, Scott M, Mastrianni J, Gabizon R, Torchia M, Cohen FE, DeArmond SJ, Prusiner SB. 1995. Prion propagation in mice expressing human and chimeric $\operatorname{PrP}$ transgenes implicates the interaction of cellular PrP with another protein. Cell 83: 79-90.
Mouse Models of Inherited PrP Prion Diseases

Telling GC, Parchi P, DeArmond SJ, Cortelli P, Montagna P, Gabizon R, Mastrianni J, Lugaresi E, Gambetti P, Prusiner SB. 1996a. Evidence for the conformation of the pathologic isoform of the prion protein enciphering and propagating prion diversity. Science 274: 2079-2082.

Telling GC, Haga T, Torchia M, Tremblay P, DeArmond SJ, Prusiner SB. 1996b. Interactions between wild-type and mutant prion proteins modulate neurodegeneration in transgenic mice. Genes Dev 10: 1736-1750.

Torres JM, Castilla J, Pintado B, Gutiérrez-Adan A, Andréoletti O, Aguilar-Calvo P, Arroba AI, Parra-Arrondo B, Ferrer I, Manzanares J, et al. 2013. Spontaneous generation of infectious prion disease in transgenic mice. Emerg Infect Dis 19: 1938-1947.

Tremblay P, Ball HL, Kaneko K, Groth D, Hegde RS, Cohen FE, DeArmond SJ, Prusiner SB, Safar JG. 2004. Mutant $\mathrm{PrP}^{\mathrm{Sc}}$ conformers induced by a synthetic peptide and several prion strains. J Virol 78: 2088-2099.

Watts JC, Giles K, Stöhr J, Oehler A, Bhardwaj S, Grillo SK, Patel S, DeArmond SJ, Prusiner SB. 2012. Spontaneous generation of rapidly transmissible prions in transgenic mice expressing wild-type bank vole prion protein. Proc Natl Acad Sci 109: 3498-3503.

Watts JC, Giles K, Patel S, Oehler A, DeArmond SJ, Prusiner SB. 2014. Evidence that bank vole PrP is a universal acceptor for prions. PLoS Pathog 10: e1003990.

Watts JC, Giles K, Serban A, Patel S, Oehler A, Bhardwaj S, Guan Y, Greicius M, Miller BL, DeArmond SJ, et al. 2015. Modulation of Creutzfeldt-Jakob disease prion propagation by the A224V mutation. Ann Neurol 78: 540-553.

Watts JC, Giles K, Bourkas ME, Patel S, Oehler A, Gavidia M, Bhardwaj S, Lee J, Prusiner SB. 2016. Towards authentic transgenic mouse models of heritable PrP prion diseases. Acta Neuropathol 132: 593-610.

Westaway D, DeArmond SJ, Cayetano-Canlas J, Groth D, Foster D, Yang SL, Torchia M, Carlson GA, Prusiner SB. 1994. Degeneration of skeletal muscle, peripheral nerves, and the central nervous system in transgenic mice overexpressing wild-type prion proteins. Cell 76: 117-129.

Yang W, Cook J, Rassbach B, Lemus A, DeArmond SJ, Mastrianni JA. 2009. A new transgenic mouse model of Gerstmann-Sträussler-Scheinker syndrome caused by the A117V mutation of PRNP. J Neurosci 29: 10072-10080.

Zahn R, Liu A, Lührs T, Riek R, von Schroetter C, López García F, Billeter M, Calzolai L, Wider G, Wüthrich K. 2000. NMR solution structure of the human prion protein. Proc Natl Acad Sci 97: 145-150. 


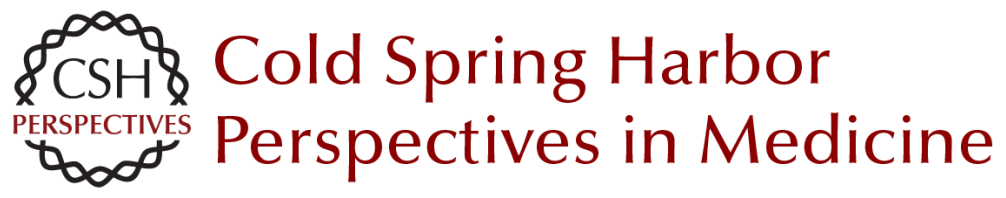

\section{Experimental Models of Inherited PrP Prion Diseases}

Joel C. Watts and Stanley B. Prusiner

Cold Spring Harb Perspect Med 2017; doi: 10.1101/cshperspect.a027151 originally published online January 17, 2017

\section{Subject Collection Prion Diseases}

TDP-43 Prions

Takashi Nonaka and Masato Hasegawa

$\alpha$-Synuclein: Multiple System Atrophy Prions

Amanda L. Woerman, Joel C. Watts, Atsushi

Aoyagi, et al.

Genetics of Synucleinopathies

Robert L. Nussbaum

$\beta$-Amyloid Prions and the Pathobiology of

Alzheimer's Disease

Joel C. Watts and Stanley B. Prusiner

Disease Mechanisms of C9ORF72 Repeat

Expansions

Tania F. Gendron and Leonard Petrucelli

Chronic Traumatic Encephalopathy: Is Latency in

Symptom Onset Explained by Tau Propagation? Joshua Kriegel, Zachary Papadopoulos and Ann C. McKee

Noncerebral Amyloidoses: Aspects on Seeding,

Cross-Seeding, and Transmission

Gunilla T. Westermark, Marcus Fändrich,

Katarzyna Lundmark, et al.

Structural and Chemical Biology of Presenilin

Complexes

Douglas S. Johnson, Yue-Ming Li, Martin

Pettersson, et al.
Cell Biology and Pathophysiology of $\alpha$-Synuclein Jacqueline Burré, Manu Sharma and Thomas C. Südhof

Molecular Mechanisms of Chronic Wasting

Disease Prion Propagation Julie A. Moreno and Glenn C. Telling

Genetics of Amyotrophic Lateral Sclerosis Mehdi Ghasemi and Robert H. Brown, Jr.

The Genetics of C9orf72 Expansions Ilse Gijselinck, Marc Cruts and Christine Van Broeckhoven

Prion-Like Characteristics of

Polyglutamine-Containing Proteins Margaret M.P. Pearce and Ron R. Kopito

Therapeutic Strategies for Restoring Tau Homeostasis

Zapporah T. Young, Sue Ann Mok and Jason E. Gestwicki

Fused in Sarcoma Neuropathology in Neurodegenerative Disease Ian R.A. Mackenzie and Manuela Neumann

Experimental Models of Inherited PrP Prion Diseases

Joel C. Watts and Stanley B. Prusiner

For additional articles in this collection, see http://perspectivesinmedicine.cshlp.org/cgi/collection/ 